Peer-Reviewed Article

ISSN: 2162-3104 Print/ ISSN: 2166-3750 Online

Volume 5, Issue 4 (2015), pp. 434-446

(C) Journal of International Students

http://jistudents.org/

\title{
Tale of the Tape: International Teaching Assistant Noticing During Videotaped Classroom Observations
}

\author{
Gwendolyn M. Williams, PhD \\ University of West Florida (USA) \\ Rod E. Case, $P h D$ \\ University of Nevada, Reno (USA)
}

\begin{abstract}
International teaching assistants face challenges in learning the norms for teaching in American universities. In order to address this learning curve this article describes a qualitative study of twenty international teaching assistants that examined how these participants viewed observations as part of their professional development. The study explored the noticing practices of international teaching assistants who participated in an initial interview, followed by a classroom observation so that the ITAs could notice their own teaching practices in the classroom. After examining the ITAs' noticing of events during observations, the article will conclude with general recommendations for effective use of observations as part of the training of international instructors.
\end{abstract}

Keywords: International teaching assistants, videotaped teaching observations, teacher noticing

The demographics of U.S. higher education continue to shift toward increasing numbers of internationals and non-native speakers of English in the teaching force. Since many foreign students are ineligible for federal grant or loan programs, they often seek assistantships to help defray educational expenses. Predominantly, many undergraduate science and math courses at research universities are taught by international teaching assistants (ITAs) (Gorsuch, 2013). Much research has been devoted to helping the ITAs to improve their language intelligibility (Chiang, 2009, 2011; Li, Mazer \& Ju, 2011) and fostering the ITAs' acculturation into the teaching norms at American universities (Chae, Lim \& Fisher, 2009; Gorsuch, 2012).

\section{Literature Review}

International instructors who are learning to teach in a new culture have a significant learning curve to master as they learn the new cultural norms that are expected in their new context. For many, the cultural norms of teaching are an implicit knowledge set that is learned through the 
participation in a schooling system as a child (Chappell, 2007). ITAs face the additional challenges of often having little or no teaching experience in any culture (LeGros \& Faez, 2012). They must master the cultural norms of schooling in American universities that are often quite different from the norms from their native culture. Accordingly, the American norms of cooperative learning and student centered teaching can be quite challenging for them to learn (Gorsuch, 2012; Chae et al. 2009; Boman, 2013). Earlier research highlighted such cultural teaching skills that ITAs need to master such as questioning and responding to questions (Chiang, 2011; Chiang \& Mi, 2011; Reinhardt, 2010), rapport building (Boman, 2013), and nonverbal communication (Gorsuch, 2012; Lazaraton \& Ishihara, 2005). Learning these cultural norms of teaching will help the ITA to offer culturally appropriate instruction for their students.

Although many universities teach ITAs the cultural pedagogical skills that are needed in order to successfully teach in the classroom, the acquisition of separate skills will not lead to overall teaching expertise until the ITA is able to evaluate their own performance for the purpose of refining their teaching skills. For many international instructors, the practice of noticing is an unfamiliar practice (Chae et al. 2009). Sherin and Van Es (2005, p. 476) describe noticing as "a new way of seeing what is happening in [the] classroom." Much of the earlier research included discussions after ITAs interacted with undergraduate students (Staples, Kang \& Wittner, 2014), but such research does not explore how ITAs notice events in their teaching. Without a video of the class as a foundation for the discussion, recall bias can affect the historical veracity of an event. A videotaped observation is especially important to ITAs who often do not have previous experience teaching or an awareness of how they appear in the classroom (LeGros \& Faez, 2012). For the purposes of this research, we were interested in how the ITAs noticed their interactions with students in an actual college classroom. This study examined how ITAs engaged in noticing aspects of their teaching through the examination of their videotaped lesson.

\section{Noticing}

Even though numerous methodologies for studying video in teacher education as well as its definition have been proposed (e.g., van Es \& Sherin, 2002; Seidel, Blomberg, \& Stürmer, 2010), Sherin and van Es (2005) propose a three-part definition of noticing that is common in many studies. First, noticing is complicated by the fact that it takes place in the classroom---a complex and interactive environment. Second, successful noticing requires the teacher to move from theory to practice in order to make connections between the larger theories which guide teaching and learning and the specific kinds of classroom practice that they must carry out every day. Finally, noticing requires teachers to make sense of how the details of their own teaching situation, e.g., age level of students, content of the course, school setting, and, of course, the teachers' cultural and social background, relate to instruction and learning.

\section{Noticing and Video}

Video has been acknowledged as a highly effective medium for improving instructional skills in its own right (Whitehead \& Fitzgerald, 2007). It represents a tool for to encourage teachers to reflect on a lesson from multiple perspectives (Spiro, Collins \& Ramchandra, 2007), a means to evaluate one's teaching outside of the pressure of the classroom (Sherin, 2004), and a powerful means of motivating self-evaluation (Roth, 2007) in a way that fosters the development of a careful and directed analysis of a lesson (e.g., van Es \& Sherin, 2002). The bulk of the research has drawn on pre- and in-service teacher population (e.g. Masats \& Dooly, 2011; Welsch \& Devlin, 2007) with fewer examples among college instructors (e.g., Chappell, 2007; 
Hall \& Smotrova, 2013). To date, research on the use of videotaped teaching observations with the ITA population is limited (e.g., LeGros \& Faez, 2012; Lazaraton \& Ishihara, 2005; Salomone, 1998). Drawing on research from both pre-service teacher education (e.g., Masats \& Dooly, 2011; Welsch \& Devlin, 2007) and the adult population (e.g., Chappell, 2007; Hall \& Smotrova, 2013), a review of the findings most relevant to the ITA population is presented below.

An ongoing theme within the use of video and noticing suggests that watching a videotape of one's teaching influences what teachers notice about their instruction (e.g., van Es \& Sherin, 2002). Early research by Sherin and van Es (2005) found that that the nature of observations varied between pre- and in-service teachers. Both groups, however, changed over time. Pre-service teachers moved from simply giving a recount of their instruction to identifying significant interactions with cooperating teachers while in-service teachers commented less on what the teacher was doing in the classroom to how the students were responding. Both groups began offering more evidence to support their assertion and changed from giving nearly all evaluative comments on the videos to offering interpretations of the events.

In a similar study, Borko, Jacobs, Eiteljorg, and Pittman (2008) used video data collected from the classrooms of 15 middle-school algebra teachers over the course of two years. Data were collected during a series of three workshops which Borko et al. (2008) titled the "Problem Solving Cycle." In the first workshop, teachers were given a mathematical task to solve and then, after solving the problem, considered how they would teach it to their students. This mathematical task was then taught and videotaped in their middle school classrooms. Workshops two and three involved the teachers in watching and discussing videos of their own classroom instruction. Facilitators framed the viewing of the second workshop around the actions of the teacher. Topics included how the teachers introduced new tasks and concepts and handled classroom discussion. In workshop three, teachers discussed students' comments and conversations about mathematics. Findings showed that teachers doubled the number of observations that they made from the time that they began workshop one to the time that they completed workshop three. Like participants in Sherin and van Es (2009), the teachers' comments also changed from descriptions and recounts of their teaching to interpretations and analyses of their students' comments and actions.

More recently, Sherin and van Es (2009) studied the influence of video clubs on what teachers notice in their instruction but also the extent to which video clubs influence teachers' instruction. Data included interviews and written samples from a group of middle-school and elementary school teachers collected over the course of a year. Findings showed notable similarities among the two groups: moving from simply giving a recount of their students' actions and comments in class to identifying ways in which the students were using mathematical thinking. The viewing and discussion of video also appeared to influence their practice. Post interviews and observations revealed that teachers were more likely to notice and act on examples of their students' mathematical thinking during instruction after participating in the video club than before.

Past research on the use of videotapes with ITAs offered findings that are simply the starting point for this research area. Salomone's (1998) study had the ITAs writing critiques of their videotaped observation after watching the tape. Additional data sources for this study were surveys, interviews, group interviews, and teaching journals. This particular study did not facilitate the watching of the video, so ITAs were left to notice elements of the lesson on their own. Although LeGros and Faez (2012) did use videotaped teaching observations as a basis for

September/October $2015 \quad$ http://jistudents.org $\quad$ Volume 5 • Issue 4


reflection, their ITAs' classroom audiences were comprised of their master's level classmates in microteaching assignment, which provides an artificial environment instead of an authentic undergraduate class. Nonetheless, the ITAs were asked to evaluate their videotape according to a teacher behavior inventory. The researchers also used the TBI to critique the videotapes. Findings from this study indicated that ITAs often overrated their teaching at the beginning of the semester but underrated their teaching at the end of the term. Additionally, Lazaraton's and Ishihara's 2005 study was a case study that explored how one ITA analyzed the use of nonverbal communication and discourse strategies as seen in her videotaped classes. Eröz-Tuğa's (2013) research utilized videotaped observations as part of an ESL teaching practicum; however, the videos were used as an evaluation tool which the university supervisor discussed with the participants as part of a voluntary extension of class requirements. In that particular study, student teachers were paired up with a peer student and a university supervisor who each evaluated the student teacher's videotaped lesson before the students teachers had a lesson that was formally evaluated for a grade. Results from this study found that the experience helped the student teacher to notice more elements of the lesson and to become more confident in the classroom.

The above research establishes that the use of video in teacher training provides a conduit to both increase the amount of conversation (Borko et al. 2008) as well as redirects teachers comments from a recount of their practice to an interpretation of their students' thinking (e.g., van Es \& Sherin, 2002). Although research has taken place with both pre- and in-service groups (e.g., Masats \& Dooly, 2011; Welsch \& Devlin, 2007) which suggests that there are differences across groups (e.g., van Es \& Sherin, 2002), not enough is known about the contribution that the ITA population can make to an understanding of video in teacher education. Moreover, the methods used in past research (e.g., LeGros \& Faez, 2012) have relied on simulated classroom settings and not on the actual classrooms where the ITAs teach. In order to understand the ways in which noticing and video interact in the classrooms of ITAs, more research needs to be carried out which is sensitive the unique strengths and backgrounds that ITAs bring to the classroom

The research question for this study was "What do international teaching assistants notice about their teaching in videotaped teaching observations?"

\section{Participants}

\section{Research Method}

This study included twenty different participants (ten males and ten females), who represented thirteen different teaching fields, and fourteen different nationalities. The recruitment at a large research university in the southeastern United States was aimed at former students of the ITA training courses, as well as at departments that had a large proportion of ITAs through the process of snowball sampling. Most of the subjects had worked as ITAs for an average of three years and had resided in the United States for an average of almost five years. All but four of the participants had taught previously before coming to the United States. Generally, the ITAs who were teaching languages were responsible for two sections of the same course and the math and science students were responsible for one section of a classroom course or a science lab. Throughout the course of the study, students were identified by pseudonyms at all times.

\section{Data Collection}

Participants took part in individual interviews where they discussed their experiences of learning to teach in an American university. 
Table 1

Demographic Chart of Participants

\begin{tabular}{lcc}
\hline Participant & Gender & Country \\
\hline 1. Shanti & $\mathrm{F}$ & India \\
2. Ravi & $\mathrm{M}$ & India \\
3. Dikembe & $\mathrm{M}$ & Cameroon \\
4. Ivan & $\mathrm{M}$ & Bulgaria \\
5. Hai & $\mathrm{M}$ & China \\
6. Lena & $\mathrm{F}$ & China \\
7. Min & $\mathrm{F}$ & S. Korea \\
8. Soo & $\mathrm{F}$ & S. Korea \\
9. Cheng & $\mathrm{M}$ & China \\
10. Ryoko & $\mathrm{F}$ & Japan \\
11. Rosa & $\mathrm{F}$ & Spain \\
12. Carlos & $\mathrm{M}$ & Spain \\
13. Lupe & $\mathrm{F}$ & Spain \\
14. Ibrahim & $\mathrm{M}$ & Burkina Faso \\
15. Daniela & $\mathrm{F}$ & Brazil \\
16. Jacques & $\mathrm{M}$ & Haiti \\
17. Isabel & $\mathrm{F}$ & Peru \\
18. Eva & $\mathrm{F}$ & Romania \\
19. Hashim & $\mathrm{M}$ & Tanzania \\
20. Hans & $\mathrm{M}$ & Austria \\
\hline
\end{tabular}

The purpose of the first interview was to gain information about the background of the students in order to understand the participant's cultural and educational background as the origin for their current educational practices and beliefs. Typical topics for the first interview included previous educational background, language learning experiences, prior teaching experiences and cross-cultural comparisons of the roles of teachers and students in the U.S. and their native cultures.

After the initial interview, each of the twenty participants was recorded teaching in the classroom for one complete class period, which ranged from fifty minutes to three hours depending on the nature of their particular teaching responsibility. The procedure for videotaping was explained beforehand so that the ITAs knew what to expect. The videotape was used to help participants to recall the segment of the lesson that the researcher wanted to discuss (Baecher, Kung, Jewkes \& Rosalia, 2013) as well as to study how the opinions in the interviews translated into classroom practice.

Predominantly, the second interview focused on clarifying information from the earlier interview and events from the observations. As the participants watched the video, the interviewer used "stopping points" to pause the tape and elicit further descriptions or clarifications about what was happening in the video (Jacobs \& Morita, 2002). Each question was designed to elicit participants to notice different elements of their teaching or to provide more information so that the researcher had a fuller understanding of the lesson. Some sample questions from the second interview were as follows: "When you said Brazilian teachers focus more on teaching you something, can you tell me more what you meant? For an introductory level, how does your students' lack of prior knowledge influence the way that you teach?" The participants' explanations of the taped observation were especially important in foreign language classrooms when the interviewer did not understand the language of instruction.

\section{Data Analysis}

The interview transcripts and videotaped observations were analyzed through narrative analysis in order to see how the participants positioned themselves as they told the stories of their teacher development as they watched the videos (Barkhuizen, 2011). As the participants viewed themselves teaching in the classroom, they were able to connect what they saw on tape to either what they were feeling or what they were intending to do in the classroom. These teachers' narratives were valuable sources of information because the stories provided the backstory on what was occurring on the videotape that might not have been apparent to the interviewer who 
watched the tape. Although the narratives served as critical sources for this study, the stories also proved to be beneficial to the participants because it provided an avenue for the participants to notice and interpret different elements of their classroom practices. Furthermore, member checking was used to clarify areas of the transcripts that were unclear. Through the interviewing process, the participant worked with the interviewer to co-construct a narrative in order to address the unique needs of a particular context. This cooperative effort enabled the participant to discuss aspects of his or her teaching that had not been considered previously. The narratives were then coded to identify the overarching themes across the different interviews to represent a collective experience (Barkhuizen, 2011). Common themes in this study were self-awareness, validation of instructional decisions, and self-evaluation.

\section{Results}

\section{Self-awareness}

For many of the ITAs in the study, the observations enabled them to gain a selfawareness of how they appeared in the classrooms. This paralleled earlier studies that found that video could be used as tool to reflect from multiple perspectives (Spiro et al. 2007). However, many of the participants remarked that they had never seen themselves on videotape as they were teaching. The new experience of being videotaped while they were teaching made many of the participants nervous. For instance, Hai, an ITA from China, acknowledged the pull between the expected norms and his behavior by commenting, "I'm kind of nervous I'm not a like, you know, actor type of person... don't know how to behave in front of a camera that's the thing. Besides that I, I had fun." While nervousness was a common emotion for many of the participants, this experience was an important moment in self-awareness as in the case of Ibrahim, an ITA from Burkina Faso, who commented, "It's bizarre to watch yourself talking." Specifically, the process of videotaping clearly distinguishes the discrepancy between instructors' self-perceived behavior and their performance that the students or supervisor see in the classroom (Baecher et al. 2013). For instance, Carlos, an ITA from Spain, found the experience of watching himself to be entertaining. During the videotaped lesson, he had made the Twilight Zone sounds for his students, so he remarked, "I entertain myself, it's great! I've never seen myself like this." In this case, the use of videotaped noticing heightened the self-awareness of the participant, which in turn led to greater monitoring of their instructional performance (Baecher et al. 2013). This awareness reaffirmed his earlier statement that "one of my mottoes is, if there has to be a clown in the class that's going to be me." The process of noticing an event in a videotape enabled the participant to focus on a specific event that may have gone unnoticed when teaching in the classroom (Seidel, Stürmer, Blomberg, Kobarg \& Schwindt, 2011). Reviewing an incident allowed the ITA to move from recount to analysis through focusing more on interpreting student behavior because they already knew their own mindset as the teacher. Noticing was particularly important for ITAs so that they could view their teaching in the context of the cultural norms of the American university classroom.

\section{Validation of Instructional Choices}

Others went further to explain how the videotape validated the personal choices that they had made in their teaching as they sought to explain their instructional decisions for the interviewer (Schoenfeld, 2013). These eureka moments offered the participants insight into teaching practices where the value of incidental comprehension that was not anticipated. 
Mindfulness of how they appear to their students allows the ITAs to make conscious decisions about their teaching. With the benefit of viewing the videotape of their teaching performance the participants were able to articulate their pedagogical choices, thus facilitating noticing about their own teacher development (Tripp \& Rich, 2012). For instance, Ravi, a TA from India, stated,

When I'm writing something on the board I don't like standing in front of things which I'm writing, so normally I'm over on the side cause you've also seen me I'm walking front, up front in case I'm not um paying any attention on the things which I've written on the board and it's kind of announcement or conclusion or summarization.

This statement demonstrated that he had given deliberate consideration to the way that he physically positioned himself in the classroom in order to improve his teaching strategies. Videotaping allowed the instructors to study their own gestures and unconscious mannerisms in teaching in order to understand what may be distracting to students (Eröz-Tuğa, 2013). Another participant, Dikembe commented on his deliberate movement in the classroom by explaining, "Only half of them raise their hand, I come and help them so... I'm moving around to see what they, what they're facing, "cause is most, most of the time new for them." Such a focus was supported by Hall and Smotrova (2013) who argued that the body was more than a physiological being; it was an integral part of the education process that could facilitate classroom management.

\section{Self-Evaluation}

Other participants used the videotape as an impetus to change their teaching practices as a result of their own self-evaluation (van Es \& Sherin, 2007). After seeing themselves on tape, they resolved to consciously work on improving various aspects of their teaching practices. Some TAs who had taken formal TA training courses were more comfortable with videotaping their teaching to analyze their own teaching performances One participant, Ibrahim, an ITA from Burkina Faso, remarked, "Oh thank you for reflecting you know teaching, reflect on your own teaching, by watching it you know... you can improve on yourself you know?" By establishing a baseline of his current performance practices, he was able to identify areas that he wanted to improve on and then make changes. Such sentiment was also expressed by Jacques, an ITA from Haiti who commented, "If you record your own teaching, and you see later on, you know, but not based on apparent knowledge." This quote indicated that videotaping allowed him to notice different things about his teaching which he may not have noticed at the time that he was teaching. Such thoughts were echoed by Min, an ITA from South Korea who explained,

I don't know if you really noticed or not, but I had a hard time finding my own stuff. (Chuckle) I put things up here and then I forgot about it. I realized that later. And I should have taught a little bit of acoustic parts without doing the pronunciation, which I didn't.

The videotape provided her with some perspective to analyze her teaching practices, whereby she was able to offer alternate ways of handling the situation. Some of the participants wanted to use video as a means for self-evaluation to improve their teaching. Hans, an ITA from Austria, remarked, "Sometimes I want to watch myself teaching to see if it is correct." This quote revealed that Hans had an internal notion of what pedagogy was expected in this context so that 
he could compare what he saw in the videotape with what he thought should have been the appropriate action in the classroom. As seen in these examples, when teachers are able to evaluate their own teaching, it promotes more of a self-empowering role in their own teacher development (Baecher et al. 2012).

Some participants were unaware that their teaching beliefs were incongruous with their teaching practices until they watched themselves on video. For example, one participant described himself as "not a teacher that lets his students go without caring." However, in the videotape, he taught most of the time with his back to the class so that he could write on the board or calculate math problems on the computer screen. When asked about his use of the blackboard, he responded, "Here's like a, show them the way, do this, do that, and they do it by themselves. The eye contact is not very crucial here, it's not very crucial." His narrative further described his interpretation of the student behavior that he had noticed, but he evaluated it as not being critical to his teaching. Other participants, such as Soo, an ITA from Korea, discussed using videotaping as part of course requirements, but she had not previously used it as a personal method of teacher development. Accordingly, the act of videotaping in itself did not always show that participants understood how videotaping could be used to promote personal professional growth (Seidel et al. 2011). However, this experience had raised the awareness of doing video-based analysis in the future as a means of teacher development for these participants.

Other ITAs engaged in noticing during the viewing of the videotape by explaining their internal thoughts to the interviewer. They recognized that as a teacher they could not always voice their opinions to the class. This inner speech of the participants revealed a different dimension to the narratives as they narrated their inner thoughts behind their outward classroom behavior. For example, Ryoko, an ITA from Japan, described her thoughts about one of her students who did not write any answers on the quiz during the observation. She explained,

I was like, "Well, look, I mean you can't..." I mean in my mind I was like, "You can't be in my class like this," but of course I would say it in a nicer way. (Laughter) Americans! (Laughter) I'm sorry.

Even though her inner thoughts labeled the student's actions as unacceptable, she represented her thoughts in a more genteel manner and tried to get the student to try to fill in some of the blanks on his test paper. Viewing the video enabled Ryoko to verbalize her thought processes that were not necessarily visible within the video itself. She was able to share her self-talk with the interviewer in order to analyze her situation and explain how she mediated the situation in order to achieve a desirable outcome (Hall \& Smotrova, 2013).

Watching the videotape with an interviewer enabled the ITA to receive cultural clarification of events that happened in the classroom. The lack of cultural knowledge was often an issue that impeded the ITAs' instruction (LeGros \& Faez, 2012). This was clearly exemplified by Daniela, an ITA from Brazil. On the videotape Daniela's class was reading a story about Fabio. Her students began to tease her because they were thinking of the famous model, Fabio. Daniela turned to the interviewer while viewing the tape and stated, "I don't know the person, who's the person?" After the researcher provided a brief description of Fabio, Daniela was more able to understand her students' reactions in the videotape because she did not understand the cultural reference in real time. Several of the participants in this study used the process of viewing the videotape to ask the interviewer questions about how to explain things in English 
after they noticed that their explanation in the videotaped class was not fully understood by their students. One such example was Isabella, an ITA from Peru, who was trying to describe a common meal in Peru, but she couldn't name it in English. She said,

We are talking according to the reading, um about food, and so can you imagine the difference, Peruvian food and American food? Even I mention there de coi, de coi is the piggy, the little animal, the piggy, (snaps fingers) I cannot remember that name.

After a few negotiations of the word "piggy" the interviewer was finally able to determine that the participant was referring to a guinea pig, and the ITA was able to go on with her analysis of this class incident. These examples illustrated that analyzing videotaped teaching observations could be enhanced when the ITA had an informant to provide background cultural and linguistic knowledge.

Beyond the realm of informant some participants wanted their mentor to provide external feedback of the videotaped teaching performance (Sherin, 2004). Videotaping differed from other types of evaluation in that it recorded the exact events that occurred in the classroom so that teachers could actually see how they appeared in the classroom (Tripp \& Rich, 2012). Some participants suggested video-taped observations could be evaluated by various stakeholders. Rosa, an ITA from Spain, remarked that "Yeah, with the camera you, you judge me" so she associated the video with the act of evaluation which had been common in established teacher education research (Hatzpinagos \& Lygo-Baker, 2006). While some participants had negative connotations about videotaping, other participants embraced the evaluation of the videotape as a way to encourage teacher growth. Eva, an ITA from Romania, explained that she wanted to use videotapes to document her teaching practice for her supervisor.

I don't want just only to participate in a passive even that my supervisor told me, you can evaluate until then, and I wanted to do something different! Why not? Just to record it and to present it to my supervisor

She viewed videotaped observations as a means of seeking outside evaluation. Getting peer feedback from others provided the participant with an element of accountability so that there was more motivation to improve their teaching practice (Tripp \& Rich, 2012). Even within the context of this particular observation she asked the interviewer to evaluate the videotape, but the interviewer explained that this was not the purpose of the interview study so the request was politely declined. Later Eva inquired, "Did you have the impression that I spoke very much little bit?" Many of the participants tried to elicit the interviewer's evaluation of the observation, most likely because feedback had been a prominent feature of previous teaching observations that they had experienced (Hatzipanagos \& Lygo-Baker, 2006). She later explained that she asked for feedback because, "Now it just uhm also because I don't see the students you know I only saw ((laughs)) myself so that also one has something to do you know?" Even though this participant admitted that multiple perspectives of noticing could provide her with more feedback (Spiro et al. 2007) such information would interfere with the participant's ability to analyze his or her own teaching. 


\section{Discussion and Conclusions}

While research into how video can contribute to noticing in the classroom among in- and preservice teachers (e.g., Masats \& Dooly, 2011; Welsch \& Devlin, 2007) as well as college instructors (e.g., Chappell, 2007; Hall \& Smotrova, 2013) has been well established, not enough is known about the unique contributions that ITAs might make this body of research. This study contributed three findings to the body of research into video and noticing by examining how the process of noticing contributed the professional growth of ITAs.

\section{Methodological Contributions}

The first contribution was methodological. Past research into noticing and video relied on simulated teaching rather than drawing on actual students in the classrooms of students, for instance by LeGros and Faez (2012). This study went a step beyond the LeGros and Faez's (2012) study to use videotaped observations in an actual classroom instead of using a mock classroom. The use of authentic classrooms enabled the ITAs to observe various aspects of the classroom interaction that might not have occurred in a fabricated classroom of peers. Secondly having the ITAs teach within their own content area rather than an assigned random topic increased their investment to improve because they saw the immediate relevance of the videotaped observation experience, such in the cases of Hans and Jacques among others, who wanted to evaluate the video to improve their own teaching. The context of a regularly scheduled undergraduate class also provided the ITAs with exposure to spontaneous authentic classroom events in order to build their teaching expertise of responding to students.

\section{The Role of Mentors in the Observation Process}

A second finding revealed how incorporating mentors into the video viewing process intersects with the cultural backgrounds of the ITAs' and their comprehension of the teaching observation process. While prior studies used mentors to discuss an evaluation of the video (Eröz-Tuğa, 2013; Baecher et al. 2013), this study used the mentor to facilitate the ITA's comprehension and analysis of the events that occurred in a videotaped lesson without offering evaluative comments. Many of the ITAs, like Daniela and Isabella, needed cultural and linguistic background in order to have a full understanding of an incident from the tape. Learning the cultural expectations of teaching was of a primary concern to many of the participants as they sought to meet the projected norms of an American college classroom. Several of the participants, like Eva, expressed the desire to record future observations to share with their university supervisors to facilitate their own professional growth. Discussing incidents of the tape with an informant enabled the ITAs, such as in the case of Ryoko, to talk through their thought processes thereby providing a space for extended analysis of events that they noticed in their teaching.

\section{The Role of Cultural Differences in Noticing}

The third and final finding demonstrated that ITAs shared many of the same experiences with noticing, e.g., being nervous while being videotaped and noticing their own gestures and unconscious mannerisms as a result of watching themselves teach, that are documented in the research (e.g., Masats \& Dooly, 2011; Welsch \& Devlin, 2007), but unlike their native speaking counterparts, ITAs linked the source of their noticing to their cultural background and not 
necessarily to their lack of teaching experience. This link to cultural differences distinguished ITAs as a unique group within the research on noticing and video.

\section{Implications}

Although this was just a preliminary study, future research in this area could contribute significantly this field. First, a study could expand on the use of videotaped observations in order to see if the initial videotaped observation and debriefing actually contributed to a change in a second videotaped observation. Additionally, the perspective of the videotape could be narrowed to focus on specific issues, such as cultural differences in interactions norms or pronunciation in the delivery of instruction to direct the noticing to certain aspects within ITAs' instruction in the university classroom. Videotaping could be implemented within an ITA pedagogy class to examine how the ITA applies pedagogical content, such as using visuals, that is learned within the ITA class to move the knowledge from theory to practice. Videotaping as part of a departmental mentoring program could provide meaningful information for discipline specific practices.

Based on these findings, we recommend that videotapes be used as a basis for future teacher training for ITAs. We believe that ITAs should watch and discuss the tape with a mentor so that the ITA is able to have guidance in noticing without evaluation since it may be an unfamiliar practice. The videotape could be watched multiple times in order to focus the ITA on a particular feature of the lesson for each specific viewing. Beyond the methodology of this study, we submit that two videotaped classes would provide more information about measuring the potential growth in pedagogical practice over time. With a second videotaped class, the ITA would be able to make strategic goals to aim for in the second videotape and to gain confidence in front of the camera. We would also suggest that videotaping should occur within actual college classrooms instead of a mock classroom so that ITAs could view themselves in an authentic teaching context.

\section{REFERENCES}

Baecher, L., Kung, S.-C., Jewkes, A. M., Rosalia, C. (2013). The role of video for selfevaluation in early field experiences. Teaching and Teacher Education, 36, 189-197. http://dx.doi.org/10.1016/j.tate.2013.08.001

Barkhuizen, G. (2011). Narrative knowledging in TESOL. TESOL Quarterly, 45(3), 391-414. doi: $10.5054 /$ tq.2011.261888

Boman, J. S. (2013). Graduate student teaching development: Evaluating the effectiveness of training in relation to graduate student characteristics. Canadian Journal of Higher Education, 43(1), 100-114. Retrieved from http://ojs.library.ubc.ca/index.php/cjhe

Borko, H., Jacobs, J., Eiteljorg, E. \& Pittman, M. E. (2008). Video as a tool for fostering productive discussions in mathematics professional development. Teaching and Teacher Education, 24(2), 417-436. doi:10.1016/j.tate.2006.11.012

Chae, J. L., Lim, J. H. \& Fisher, M. H. (2009). Teaching mathematics at the college level: International TAs' transitional experiences. PRIMUS, 19(3), 245-259. doi: 10.1080/10511970701700929

Chappell, A. (2007). Using teaching observations and reflective practice to challenge conventions and conceptions of teaching in geography. Journal of Geography in Higher Education, 31(2), 257-268. doi: 10.1080/03098260601063651

\begin{tabular}{lll}
\hline September/October 2015 & http://jistudents.org & Volume $5 \bullet$ Issue 4
\end{tabular}


Chiang, S.-Y. (2009). Dealing with communication problems in the instructional interactions between international teaching assistants and American college students. Language and Education, 23(5), 461-478. doi: 10.1080/09500780902822959

Chiang, S.-Y. (2011). Pursuing a response in office hour interactions between US college students and international teaching assistants. Journal of Pragmatics, 43(14), 3316-3330. doi:10.1016/j.pragma.2011.07.001

Chiang, S. -Y. \& Mi, H.-F. (2009). Reformulation: a verbal display of interlanguage awareness in instructional interactions. Language Awareness, 20(2), 134-149. doi:10.1080/09658416.2011.559243

Eröz-Tuğa, B. (2013). Reflective feedback sessions using video recordings. ELT Journal, 67(2), 175-183. doi:10.1093/elt/ccs081

Gorsuch, G. J. (2012). International teaching assistants' experiences in educational cultures and their teaching beliefs. The Electronic Journal for English as a Second Language, 16 (1), 1-26. Retrieved from http://www.tesl-ej.org/wordpress

Gorsuch, G. J. (2013). Helping international teaching assistants acquire discourse intonation: explicit and implicit L2 knowledge. The Journal of Teaching English for Specific and Academic Purposes, 1(2), 67-92.

Hall, J. K. \& Smotrova, T. (2013). Teacher self-talk: Interactional resource for managing instruction and eliciting empathy. Journal of Pragmatics, 47(1), 75-92. doi:10.1016/j.pragma.2012.11.017

Hatzipanagos, S. \& Lygo-Baker, S. (2006). Teaching observations: Promoting development through critical reflection. Journal of Further and Higher Education, 30(4), 421-431. doi: 10.1080/03098770600965425

Jacobs, J. K. \& Morita, E. (2002). Japanese and American teachers' evaluations of videotaped mathematics lessons. Journal for Research in Mathematics Education, 33(3), 154-175. doi:10.2307/749723

Lazaraton, A. \& Ishihara, N. (2005). Understanding second language teacher practice using microanalysis and self-reflection: A collaborative case study. Modern Language Journal, 89(4), 529-542. doi: 10.1111/j.1540-4781.2005.00328.x

Li, L., Mazer, J. P. \& Ju, R. (2011). Resolving international teaching assistant language inadequacy through dialogue: Challenges and opportunities for clarity and credibility. Communication Education, 60(4), 461-478. doi: 10.1080/03634523.2011.565352

LeGros, N. \& Faez, F. (2012). The intersection between intercultural competence and teaching behaviors: A case of international teaching assistants. Journal on Excellence in College Teaching, 23(3), 7-31. Retrieved from http://celt.muohio.edu/ject/index.php

Masats, D. \& Dooly, M. (2011). Rethinking the use of video in teacher education: A holistic approach. Teaching and Teacher Education, 27(7), 1151-1162. doi:10.1016/j.tate.2011.04.004

Reinhardt, J. (2010). Directives in office hour consultations: A corpus-informed investigation of learner and expert usage. English for Specific Purposes, 29(2), 94-107. doi:10.1016/j.esp.2009.09.003

Roth, W.-M. (2007). Epistemic mediation: Video data as filters for the objectification of teaching by teachers. In R. Goldman, R. Pea, B. Barron, \& S. J. Derry (Eds.), Video research in the learning sciences (pp. 383-396). Mahwah, NJ: Lawrence Erlbaum.

Salomone, A. M. (1998). Communicative grammar teaching: A problem for and a message from international teaching assistants. Foreign Language Annals, 31(4), 552-568. 
Schoenfeld, A. H. (2013). Classroom observations in theory and practice. ZDM: The International Journal on Mathematics Education, 45(4), 607-621. doi: 10.1007/s11858012-0483-1

Seidel, T., Stürmer, K., Blomberg, G., Kobarg, M. \& Schwindt, K. (2011). Teacher learning from analysis of videotaped classroom situations: Does it make a difference whether teachers observe their own teaching or that of others? Teaching and Teacher Education, 27(2), 259-267. doi: 10.1016/j.tate.2010.08.009

Seidel, T., Blomberg, G. \& Stürmer, K. (2010). "Observer" Validierung eines videobasierten instruments zur Erfassung der professionellen Wahrnehmung von Unterricht. Zeitschrift für Pädagogik, 56(Beiheft), 296-306.

Sherin, M. G. (2004). New perspectives on the role of video in teacher education in J. Brophy (Ed.), Using video in teacher education (pp. 1-27). NY: Elsevier Science.

Sherin, M. G \& van Es, E. A. (2005). Using video to support teachers' ability to notice classroom interactions. Journal of Technology and Teacher Education, 13(3), 475-491. Retrieved from http://www.aace.org/pubs/jtate/

Sherin, M. G. \& van Es, E. (2009). Effects of video club participation on teachers' professional vision. Journal of Teacher Education, 60(1), 20-37. doi: 10.1177/0022487108328155

Spiro, R. J., Collins, B. P. \& Ramchandran, A. (2007). Reflections on a post-Gutenberg epistemology of video use in ill-structured domains: Fostering complex learning and cognitive flexibility. In R. Goldman, R. Pea, B. Barron, \& S. J. Derry (Eds.), Video research in the learning sciences (pp. 93-100). Mahwah, NJ: Lawrence Erlbaum.

Staples, S., Kang, O. \& Wittner, E. (2014). Considering interlocutors in university discourse communities: Impacting U.S. undergraduates' perceptions of ITAs through a structured contact program. English for Specific Purposes, 35, 54-65. doi; 10.1016/j.esp.2014.02.002

Tripp, T. R. \& Rich, P. J. (2012). The influence of video analysis on the process of teacher change. Teaching and Teacher Education, 28(5), 728-739. doi: 10.1016/j.tate.2012.01.011

van Es, E.A. \& Sherin, M.G. (2002). Learning to notice: Scaffolding new teachers' interpretations of classroom interactions. Journal of Technology and Teacher Education, 10(4), 571-596. Retrieved from http://www.aace.org/pubs/jtate/

Welsch, R. G. \& Devlin, P. A. (2007). Developing preservice teachers' reflection: Examining the use of video. Action in Teacher Education, 28(4), 53-61. doi: $10.1177 / 0888406411420887$

Whitehead, J. \& Fitzgerald, B. (2007). Experiencing and evidencing learning through self-study: New ways of working with mentors and trainees in a training school partnership. Teaching and Teacher Education, 23(1), 1-12. doi: 10.1177/0022487110396096

\section{AUTHORS}

GWENDOLYN M. WILLIAMS, PhD, is an assistant professor of ESOL Education. Her research interests include teacher education and second language writing. Email: eslresearcher@gmail.com

ROD E. CASE, Ph.D., is an associate professor of TESOL. His research interests include applied linguistics and second language pragmatics. Email: rcase@unr.edu 